\title{
Carlo Forlanini, inventor of artificial pneumothorax for treatment of pulmonary tuberculosis
}

\author{
ALEX SAKULA
}

The year 1882 was an annus mirabilis in the history of pulmonary tuberculosis, for it saw not only the discovery of the tubercle bacillus by Robert Koch but also the introduction of artificial pneumothorax treatment by Carlo Forlanini. At that time Koch's spectacular achievements and the exaggerated expectations raised after the introduction of tuberculin tended to overshadow the significance of Forlanini's contribution to the management of pulmonary tuberculosis. In modern times drug treatment has eclipsed the former methods of collapse therapy, but for some 40 years before the introduction of antituberculous drugs artificial pneumothorax offered hope and in many cases cure to tuberculous patients around the world.

The centenary of the start of Forlanini's pioneer work on collapse therapy in pulmonary tuberculosis provides a suitable occasion to pay tribute to this great Italian phthisiologist (fig 1).

\section{Life of Carlo Forlanini}

Carlo Forlanini was born on 11 June 1847 in Milan, the son of a physician, Giuseppe Forlanini. Carlo was the eldest of a family of four brothers and one sister. As a lad he often accompanied his father on his rounds; he was initially undecided whether to embark on a career in engineering or medicine but finally decided on the latter. His medical studies at Pavia were temporarily interrupted in 1866 when he volunteered to serve under Garibaldi. A close friend in his student days was Camillo Golgi (1843-1926), who was later to achieve eminence as a histologist and received the Nobel Prize in 1906. Forlanini graduated MD Pavia in 1870 with a thesis, Contribuzione alla Teoria della Piogenesi.

After qualification Forlanini was at first attracted towards the specialty of ophthalmology and in 1871 published a paper on inflammation of the lens"Studio sperimentale sulla inflammazione del cristallino." In the same year he moved to Milan on

Address for correspondence: Pilgrims Corner, Pilgrims Way, Reigate, Surrey.

Accepted 3 December 1982 being appointed to the staff of the Ospedale Maggiore, where he was to spend the next 13 years. He worked in the departments of chronic diseases, eye diseases, and skin diseases, becoming the head of the skin department in 1881; but his interest in general medicine and especially diseases of the lungs and tuberculosis remained paramount. He later became assistant professor and chief physician to the medical wards, which included beds for tuberculous patients. In 1884 Forlanini was called to the chair of clinica propedeutica at Turin, where he taught clini$\mathrm{cal}$ diagnosis at the Ospedale di San Giovanni. He remained at Turin until 1889 when he was recalled to his alma mater at Pavia as Professor of Medical Pathology, and taught at the Ospedale San Mateo. Finally, in 1900 at the age of 53 he obtained the chair of clinical medicine at Pavia.

By all accounts Forlanini was a popular teacher, preparing his lectures meticulously. Among his pupils were Umberto Carpi, Eugenio Morelli, and Scipione Riva-Rocci. Carpi and Morelli were later to make important contributions to the collapse therapy of pulmonary tuberculosis, while RivaRocci achieved fame when he introduced the first practical sphygmomanometer in 1896.

Forlanini had an attractive personality, was a good conversationalist, and was cultivated in music and art. He was very much the beloved physician to his hospital patients and was content to pursue his researches without desire for personal aggrandisement. It is told that he rejected an invitation by Sir Ernest Cassel to come to England for a consultation on an important patient. Forlanini did not marry. In 1913 he became a senator and at the time of his death had been proposed for the Nobel Prize in Medicine.

Forlanini suffered from severe attacks of migraine. His terminal illness was due to an abdominal malignancy, probably carcinoma of the pancreas. He died at Nervi in his 71st year on 25 May 1918.

\section{Forlanini's early interest in aerotherapy}

In 1875 Forlanini developed an interest in aerotherapy, originally conceived by Thomas Beddoes 326 


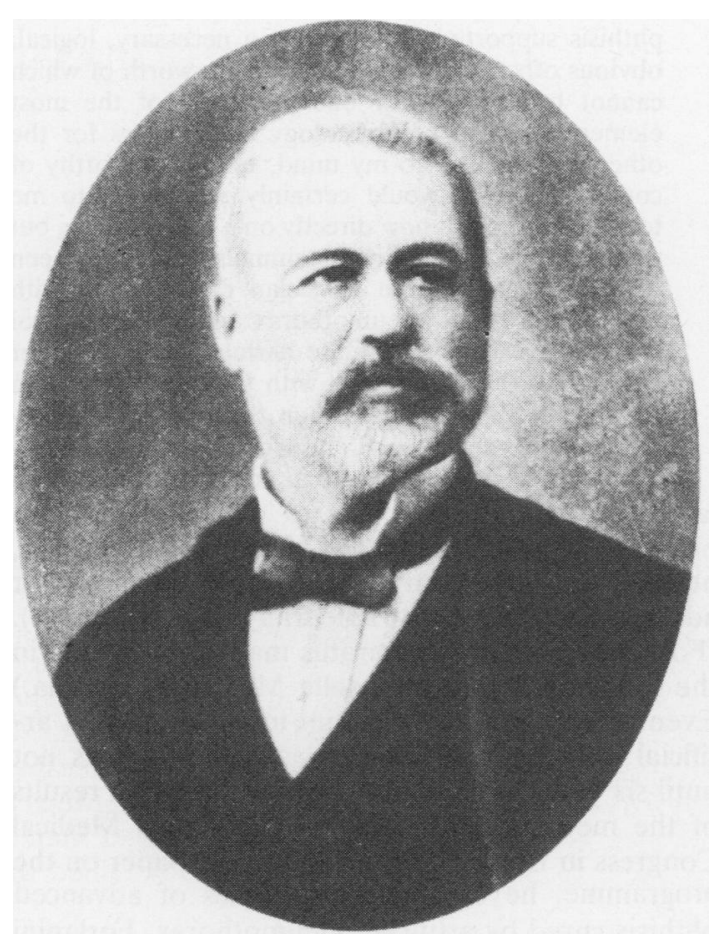

Fig 1 Carlo Forlanini. Reproduced by courtesy of the Wellcome Institute Library, London.

(1761-1808), who founded his Pneumatic Institute at Bristol in 1798. This venture proved to be unsuccessful, although Humphrey Davy discovered the anaesthetic properties of nitrous oxide in 1799 while assistant to Beddoes. In 1832 aerotherapy was introduced in France by Emile Tabarié of Montpellier, but it was JA Fontaine's revival of the technique in Paris in 1872 which attracted Forlanini's attention.

Forlanini enlisted the help of a younger brother, Enrico Forlanini (1848-1930), a brilliant engineer, the inventor of the hydrofoil and pioneer of aeronautics, after whom the Milan airport at Linate-Aeroporto Forlanini-is now named. The two brothers improved Fontaine's apparatus and in 1875 the Istituto Pneumoterapia was opened in Milan. Forlanini published several papers on aerotherapy (Brevissimi cenni . . ., 1877-89). From 1877 the institute had its own journal, Rivista di aero- $e$ climatoterapie, which in 1880 became incorporated into the Gazzetta degli Ospedale $e$ delle Cliniche di Milano.

Aerotherapy consisted essentially of the administration of compressed air for help in cardiorespirat- ory disorders. The theoretical basis of the treatment was to improve blood oxygenation, and the modification of intestinal gas pressure was also claimed to lower the level of the diaphragm with beneficial effect on cardiopulmonary function. Forlanini was cautious in using the treatment in pulmonary tuberculosis, especially in pyrexial cases, but these early experiences with aerotherapy were the prelude to his later researches into collapse therapy for pulmonary tuberculosis.

\section{Collapse therapy before Forlanini}

That a pneumothorax might assist the healing of a tuberculous lung was first suggested in 1771 by Edmond Claud Bourru (1737-1823), librarian to the Faculté de Médecine, Paris, in the preface to his French translation of Ebenezer Gilchrist's The Use of Sea Voyages in Medicine, Particularly in a Consumption and Observations on that Disease.

It was, however, the Liverpool physicianphysiologist James Carson (1772-1843) who in 1822 first applied himself seriously to the problem and showed, in experiments on rabbits, that incision of the chest wall resulted in a pneumothorax and collapse of the lung without appreciable interference with the rabbit's activities. Recognising that "consumption crops the flower of the human race," Carson thought that an attempt at producing an artificial pneumothorax in the human was justified, although he recognised the potential risk of complete collapse of the diseased lung (Lesions of the Lung, 1822).

On 26 September 1822 Carson persuaded a Liverpool surgical colleague, Mr Henry Bickersteth, to produce a pneumothorax in two tuberculous patients. The incision through the parietal pleura failed, however, to produce a pneumothorax because of pleural adhesions. After this abortive attempt the idea of collapse therapy fell into oblivion.

There were occasional reports later of the observed beneficial effect of the development of a pneumothorax or hydropneumothorax on the course of phthisis (James Houghton, 1832; David McRuer, 1835; Walter Hayle Walshe, 1860). In 1827 the great Dublin physician William Stokes noted: "Phthisis complicated with empyema and pneumothorax from fistula ... the interesting fact that the proper symptoms of phthisis are in many cases arrested, and singularly modified, by the occurrence of the new disease." In 1885 William Cayley, physician to the Middlesex Hospital, London, had a phthisical patient with severe haemoptysis and persuaded his surgical colleague, $\mathrm{Mr}$ Pearce Gould, to insert a tube into the pleura. The haemoptysis was controlled but the patient died 
later of miliary tuberculosis.

There were further developments in France. Claud Potain introduced sterilised air into the pleura to replace aspirated fluid and considered that keeping the lung collapsed in this fashion benefited the phthisical patient. Potain's pupil Emile Toussaint, in his thesis for the MD Paris (1880), described the beneficial effect of spontaneous pneumothorax in 24 cases of phthisis, but he did not advocate producing a pneumothorax artificially as a therapeutic measure. Toussaint's publication was followed by two similar case reports by Herard (1881) and Meusnier (1881).

\section{Forlanini's invention of artificial pneumothorax}

From early in his career Forlanini had developed an intense interest in the problems of tuberculosis, his first paper on the subject being a report entitled "A case of tuberculosis of the myocardium with large nodes," presented at a hospital staff meeting in 1874. From 1874 to 1882 Forlanini published nine further papers on phthisis.

After reading the papers of Toussaint, Herard, and Meusnier, Forlanini began to consider seriously the possibility of using artificial pneumothorax as a treatment for phthisis. He was not aware at that time of the work carried out by Carson 60 years earlier. In fact, it was not until 1909 that Carson's writings, which had remained virtually unnoticed until then, were brought to light by Daus.

From August to November 1882 there appeared in the Gazzetta degli Ospedale e delle Cliniche di Milano a series of 11 short papers in which Forlanini considered all aspects of his proposed artificial pneumothorax therapy for phthisis. Forlanini began the first of these papers thus:

"I am going to peer into the field of the future therapy of pulmonary tuberculosis as an explorer, with an unsafe base of operations in an unknown country. Because who can say that we know today much-or enough-of the nature and therapy of phthisis?"

After a comprehensive analysis of the case reports of Toussaint, Herard and Meusnier, Forlanini asked:

"The question is this (and it is a wonder that Toussaint, Herard, Meusnier and all those that have seen even one patient or read only one history, did not ask it): Surgeons have either let air enter the pleura, or have injected it for therapeutic purposes, both with no harmful consequences: if a pneumothorax arrests, as such, the course of phthisis in a lung, if a hydrothorax or pyothorax have formed by way of pulmonary paths: why should we not cause in a consumptive an artificial pneumothorax through the chest wall with the necessary precautions (easy to obtain) that will be useful in preventing secondary pleuritic processes? The question is certainly worthy of examination."
Forlanini concluded his series of papers thus:

"I see the proposition of artificial pneumothorax in phthisis supported moreover as a necessary, logical, obvious offspring of clinical facts, the worth of which cannot be omitted for one part, and of the most elementary ideal of physiology and physics for the other part. It has, to my mind, requisites worthy of consideration. It would certainly seem rash to me today to attempt it now directly on a consumptive, but when by experimentation on animals it will have been demonstrated that the physician can quantify with precision artificial pneumothorax and always control its volume, and the absolute harmlessness of proper gases, brought into contact with the pleura, will also have been demonstrated, then the operative procedure should seem logical and legitimate."

From such careful theoretical considerations Forlanini proceeded cautiously to put his ideas into practice. With the assistance of his brother Enrico, he designed and constructed a simple apparatus for administering gases intrapleurally (figs 2 and 3 ). (Forlanini's original apparatus may now be seen in the Museo per la Storia della Medicina in Pavia.) Eventually, in 1888, Forlanini induced the first artificial pneumothorax (fig 4), although it was not until six years later that he reported the first results of the method, at the 11th International Medical Congress in Rome. In the last but one paper on the programme, he described two cases of advanced phthisis cured by artificial pneumothorax. Forlanini used a closed method of administering nitrogen (he used this gas because its absorption was slower than that of oxygen) via a large hypodermic needle. Initially $200-250 \mathrm{ml}$ nitrogen was introduced; it was then given on alternate days and eventually at intervals of one week or longer. These findings were later reported in the Gazzetta Medica di Torino (1894), while the Münchener Medizinische Wochenschrift carried the following summary of Forlanini's report to the congress:

"Based on the repeated favourable influence of pleural fluid and of pneumothorax in the course of phthisis, Forlanini had made a research on the living and treated two cases with favourable results. The pneumothorax can naturally be used only on one side. The pleura bears the presence of air well, any reaction or irritation or any harmful influence cannot be observed. Oxygen was more quickly absorbed than nitrogen which is now used to produce pneumothorax. The operation must be slowly and gradually performed, each day a small quantity of nitrogen introduced; if it be absorbed the quantity must be increased. The absorptive capacity of the pleura lessens as time goes on. After some months the interval between injections can be lengthened."

In the following year, 1895, Forlanini reported in the Gazzetta Medica di Torino the successful outcome of artificial pneumothorax in a further case of phthisis. Forlanini then continued to treat more 


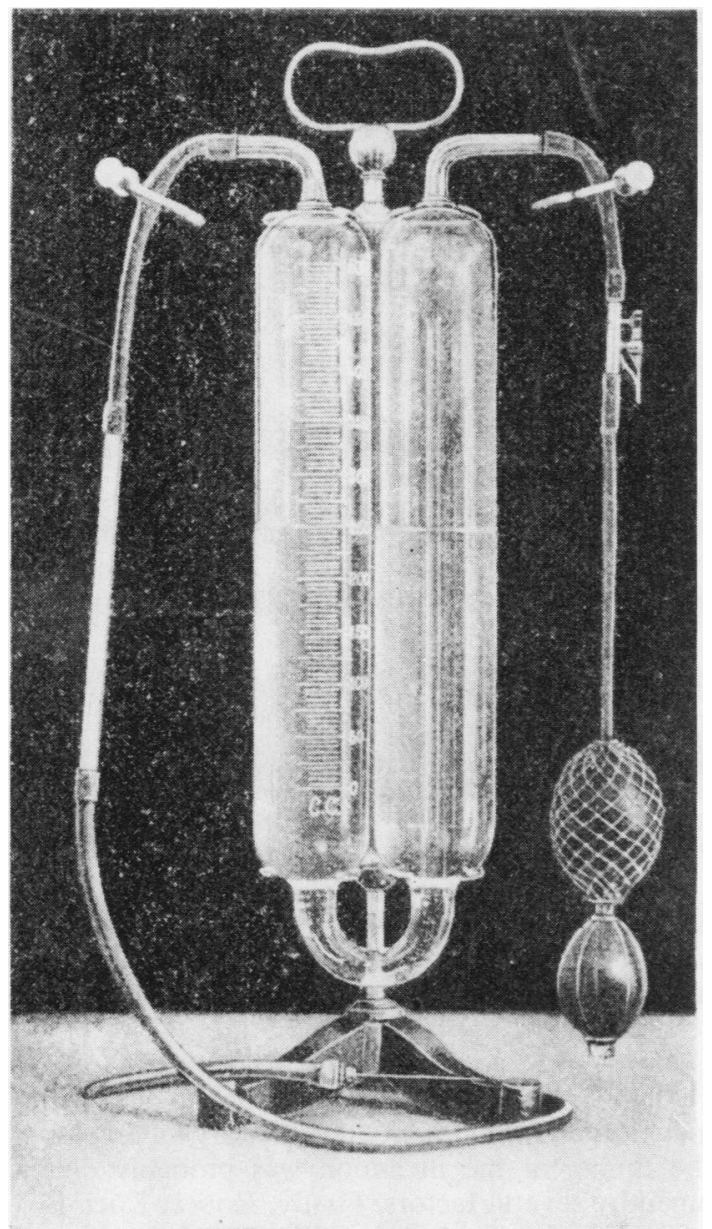

Fig 2 Forlanini's original apparatus for artificial pneumothorax. From Forlanini C. Die Therapie der Gegenwart 1908;49:488. Reproduced by courtesy of the Wellcome Institute Library, London.

tuberculous patients, but it was not until 1906 that he published a fuller report based on 25 cases.

\section{Priority of invention of artificial pneumothorax therapy}

The paper which Forlanini published in 1906 appeared in the Deutsche Medizinische Wochenschrift and the reasons why he published in a German rather than an Italian journal are of interest. Firstly, Forlanini's earlier reports of 1882 and 1895 in Italian journals did not elicit a favourable response or support from his Italian colleagues. Secondly, a paper submitted to a French journal had been rejected. Thirdly, the appearance of a paper on

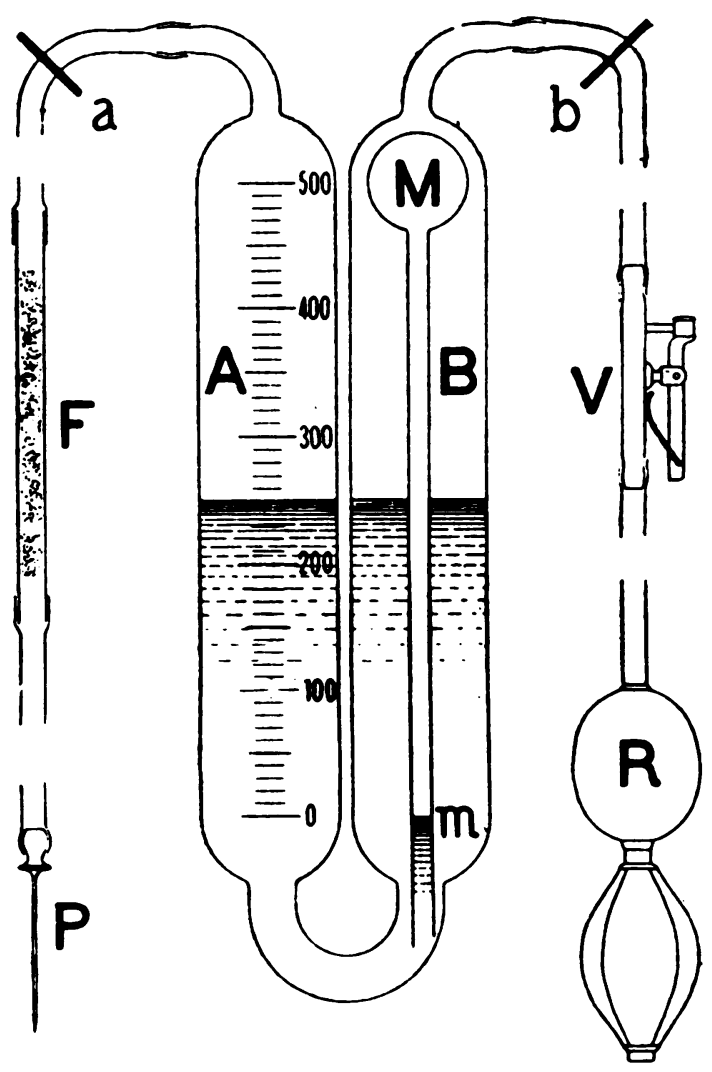

Fig 3 Diagram of Forlanini's original apparatus. $A-$ calibrated nitrogen reservoir; $B$-control reservoir; $M, m-$ manometer; $a, b-c l i p s ; V-v a l v e ; R-$ double hand pump; $F$ - filter; $P \longrightarrow$ needle. Reproduced by courtesy of the Wellcome Institute Library, London (from same paper as fig 2).

artificial pneumothorax in a German journal by Brauer (1906), who ascribed the method to the American surgeon JB Murphy, forced Forlanini to stake his claim for priority and to do so in a German journal.

The story of the part played by the great Chicago surgeon John Benjamin Murphy (1857-1916) in the history of artificial pneumothorax for phthisis may be briefly told here. At the annual meeting of the American Medical Association in 1898 Murphy was invited to deliver the Oration on Surgery and he chose as his subject "The Surgery of the Lung." He devoted some time to a discussion of the problem of tuberculosis and its surgical treatment by thoracoplasty and extrapleural pneumothorax, but also related his experience of artificial intrapleural pneumothorax. Murphy made no mention of Forla- 


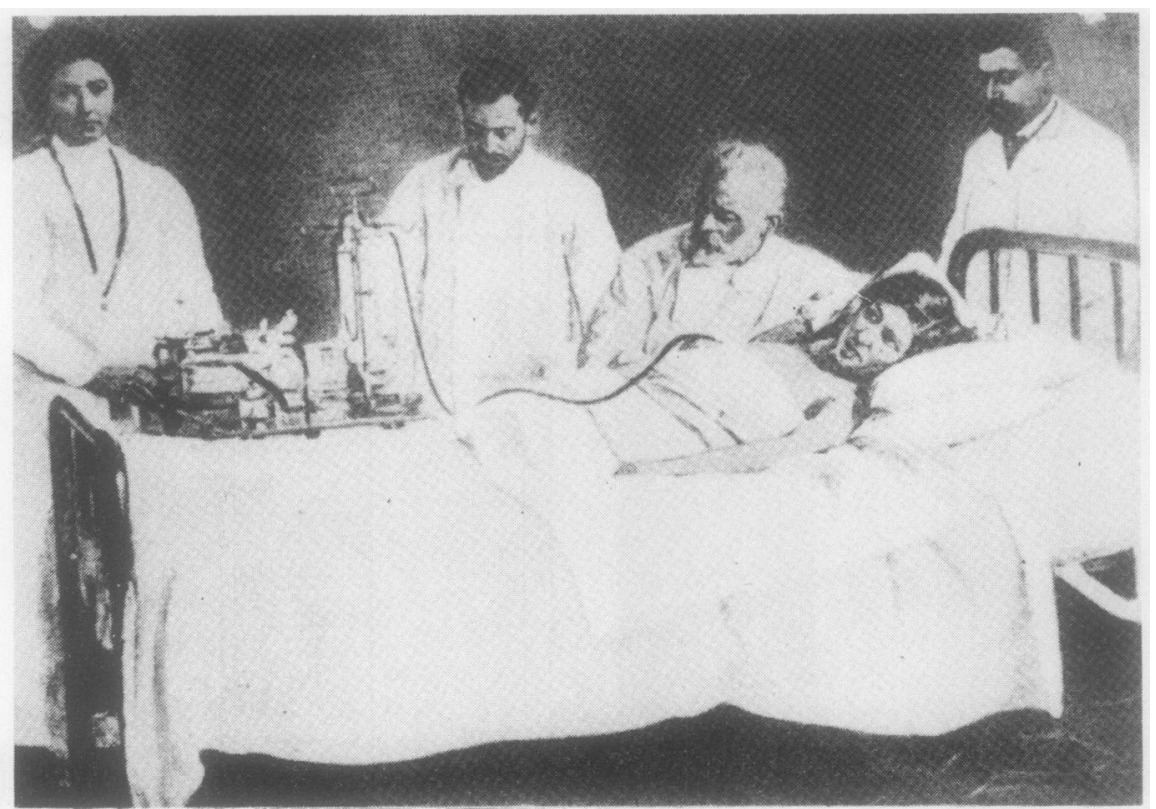

Fig 4 Forlanini administering artificial pneumothorax. From Am Rev Tuberc 1928;18:101.

Reproduced by courtesy of Wellcome Institute Library, London.

nini and presumably was unaware that this treatment had preoccupied Forlanini during the previous 16 years. In performing artificial pneumothorax Murphy incised the skin and muscle and, through the apparatus which he had himself designed, he introduced nitrogen in much larger quantities $(1000-3000 \mathrm{ml})$, further refills being equally large although infrequent. Roentgen had discovered $x$-rays in 1895 , and Murphy's 1898 paper was the first to describe $x$-ray control of artificial pneumothorax. Of the seven cases which Murphy reported, cure was claimed in five, although his follow-up was quite inadequate. Murphy did not subsequently carry out any further artificial pneumothorax treatment, which he considered sufficiently simple to be performed by a physician! Murphy's assistant, August Lemke, later reported on a series of cases (1899) but the method was not generally adopted in the United States at that time.

Murphy's method of artificial pneumothorax was, however, taken up in Germany. Ludolph Brauer of Marburg used the method for treating a series of tuberculous patients and when he published his findings (1905-06) he described it as Nach Murphy, which suggested that Murphy had been the originator of the method. It was this which stimulated Forlanini to write his 1906 report (and have it published in a German journal) to contradict the idea that Murphy had introduced the treatment and to establish priority for his invention. Forlanini was also opposed to Murphy's version of the treatment, in which open incision was used and very large volumes of gas were introduced intrapleurally, with resultant overcompression of the lung.

There can be no doubt that it is Forlanini to whom credit must be given for the introduction of artificial pneumothorax treatment of pulmonary tuberculosis. The timing of the invention was probably determined by several factors. Firstly, Robert Koch had announced the discovery of the tubercle bacillus at the meeting of the Berlin Physiological Society on 22 March 1882, the report of which was published three weeks later. Koch's discovery provided a boost to all workers in the field of tuberculosis and no doubt stimulated Forlanini to renew his efforts to discover a cure for the disease. Five months later Forlanini was already writing of artificial pneumothorax. At a later stage, when treatment using Koch's tuberculin proved so disappointing, there was a still greater need to discover an alternative therapy. Secondly, the reports from France of Toussaint (1880) and others on the benefit of spontaneous pneumothorax in phthisis directed Forlanini's thoughts towards collapse therapy. Thirdly, the growing appreciation of the bacteriological basis of infection was given special prominence at the Seventh International Medical Congress held in London in August 1881. Developments in antisepsis and asepsis must have increased Forlanini's confidence when he was considering active interven- 
tion in the chest in the presence of lung infection. Fourthly, Forlanini's mechanical flair and his collaboration with his engineer brother Enrico enabled him to combine the medical and engineering sciences to construct the first apparatus for performing artificial pneumothorax.

\section{Later developments in artificial pneumothorax therapy}

After 1895, Forlanini's ideas still met with some indifference and even hostility among his Italian colleagues. He persevered, however, and steadily perfected the technique of artificial pneumothorax treatment so that by 1912 , at the Seventh International Tuberculosis Congress in Rome, he was able to present an authoritative report, for which he received a great ovation. After 30 years of being virtually ignored his work was now universally acclaimed. Forlanini, however, was already concerned that artificial pneumothorax should not be misused and at the 1912 congress he said, "The therapy of pneumothorax is an aristocratic therapy [una terapia aristocratica], but everybody now carries it out when only a few people should perform it."

After 1912 artificial pneumothorax came to be widely adopted in Europe and the United States. There were many improvements of the original apparatus and technique. Only brief mention will be made here of the introduction of the water manometer by Christian Saugman (1906); the concept of partial collapse (or relaxation) of the lung and therefore the possibility of bilateral artificial pneumothorax therapy, advocated by Maurizio Ascoli (1912); and thoracoscopy and cauterisation of adhesions, introduced by Hans Christian Jacobaeus (1913). All these developments and many more served to increase the success rate of the treatment.

\section{The Carlo Forlanini Institute, Rome}

When Forlanini died in 1918, he had the satisfaction of knowing that his ideas on collapse therapy had been adopted throughout the world. His many pupils and admirers, both Italian and foreign, wished to create a suitable living memorial to the master. A research fund for the study of tuberculosis was founded in his name shortly after his death. Chiefly through the inspiration of his favourite pupil, Eugenio Morelli (1881-1968), the Carlo Forlanini Institute in Rome was founded in 1934. Morelli was the first director (1934-1945) and he was succeeded by his pupil Attilio Omedei-Zorini (1945-68), who was followed by a series of dis- tinguished Italian phthisiologists. The institute now comprises a complex of sanatorium, university clinic, laboratories, museum, and research centre. Both tuberculous and non-tuberculous diseases of the chest are handled at the institute, which remains a major Italian centre for the study of diseases of the chest, and constitutes a fitting memorial to the great Carlo Forlanini.

\section{Forlanini's major publications}

1875 Brevissimi cenni di Aeroterapia e sullo Stabilimento Medico-pneumatica di Milano. Gazzetta Medica Italiana Lombardia Serie VII: 6.

1882 A contribuzione della terapia chirurgica della tisi: Ablazione del pulmone? Pneumotorace artificiale? Gazzetta degli Ospedale e della Cliniche di Milano $3: 537,585,601,609,617,625,641,657,665,689$, 705.

1894 Primo tentativi di pneumotorace artificiale della tisi pulmonare. Gazzetta Medica di Torino 45:381-4, 401-3.

1895 Primo caso di tisi pulmonare monolaterale avanzata curato felicimente col pneumotorace artificale. Gazzetta Medica di Torino 46:857.

1906 Zur Behandlung der Lungenschwindsucht durch künstliche erzeugten Pneumothorax. Deutsche Medizinishe Wochenschrift 32:1401-5.

1909 Cenni storici e critici sul pneumotorace artificiale nella tisi pulmonare. In: Cappelli, ed. Scritti di Forlanini. Bologna, 1928:1013.

1912 Il pneumotorace artificiale nella cura della tisi pulmonare. Atti de VII Congresso Internazionale Contra la Tuberculosi. Vol 3. Rome, 182.

\section{Selected bibliography}

Ascoli M. Uber den künstlichen Pneumothorax nach Forlanini. Deutsche Medizinische Wochenschrift 1912; 38:1782.

Balboni GM. The development of the treatment of pulmonary tuberculosis from 1696 to the present time. $N$ Engl J Med 1935;212:1020-7.

Bock-Berti G, Vial F, Heymans G, Rulliere R. Considerazioni critiche sull' opera di Carlo Forlanini (18471918). Minerva Medica 1980;71:1879-83.

Bock-Berti G. Carlo Forlanini e l'aeroterapia. In: Proceedings of the 28th International Congress for History of Medicine, Paris (in press).

Bottero A. Carlo Forlanini: inventore del pneumotorace artificiale. Milan: Hoepli, 1947.

Bourru EC. L'utilité des voyages sur mer pour la cure des maladies differentes et notamment de la phthisie. Paris, 1771. (Translation of Ebenezer Gilchrist. The use of sea voyages in medicine particularly in a consumption and observations on that disease. London, 1771.)

Brauer L. Die Behandlung der enseltigen Lungenphthisis mit künstlichen Pneumothorax (nach Murphy). Munch Med. Wochenschr 1906;53:338-9.

Brown L. The story of clinical pulmonary tuberculosis. Baltimore: Williams and Wilkins, 1941.

Carpi U. Per la storia del pneumotorace artificiale. Rivista 
di Patologia e Clinica della Tuberculosis 1928:104.

Carson J. Essays, Physiological and Practical. Liverpool: Wright, 1822:64.

Cayley W. A case of haemoptysis treated by the induction of pneumothorax so as to collapse the lung. Transactions of the Clinical Society of London 1885;18:278.

Daus S. Historisches und kritische uber küntslichen pneumothorax bei lungenschwindsucht. Die Therapie der Gegenwart 1909;1:221, 277.

Devoto L. Il pneumotorace di Carlo Forlanini-ed il suo cinquantennio. Gazzetta degli Ospedale e delle Cliniche di Milano 1932;19:5.

Herard A. De l'influence favorable de l'hydropneumothorax sur la marche de la phthisie. Gazette des Hôpitaux 1881;90:713.

Houghton J. Account of a remarkable case of pneumothorax. Dublin Journal of Medical Science 1832;1:313.

Keers RY. Pulmonary tuberculosis: a journey down the centuries. London: Baillière Tindall, 1978:107-18.

Lemke AF. Report of cases of pulmonary tuberculosis treated with intrapleural injections of nitrogen, with a consideration of the pathology of compression of the tuberculous lung. JAMA 1899;33:959, 1023, 1077.

Lojacono S. Forlanini's original communication on artificial pneumothorax. Tubercle 1934;16:54-60, 61-87.

McRuer D. Consumption. Boston Medical and Surgical Journal 1835;12:10.

Meusnier P. De l'influence de l'hydropneumothorax sur la marche de la tuberculisation pulmonaire. Gazette des Hôpitaux 1881;110:875.
Morelli E. Carlo Forlanini e il pneumotorace. Rome, 1928.

Murphy JB. Surgery of the lungs. JAMA 1898;31:151-65, 208-16, 281-97, 341-56.

Pende M. L'opera delle Scuole Cliniche Italiane nell' applicazione della scoperta di Roberto Koch. Riforma Medica 1932;50:1903.

Potain C. Des injections intrapleurales d'air sterilisé dans le traitement des épanchements pleuraux consecutifs au pneumothorax. Bulletin de l'Academie Médicale 1888;19:537.

Riva-Rocci S. Contributo agli sulla natura del processo tisiogeno dei pulmoni. Milan: Morgagni, 1890:part 1, $1-6$.

Ronzoni G. Carlo Forlanini and the contribution of the Italian school of pulmonary collapse therapy. American Review of Tuberculosis 1928;18:101-8.

Sakula A. Robert Koch: centenary of the discovery of the tubercle bacillus 1882. Thorax 1982;37:246-51.

Saugman C. Uber die Anwendung des künstlichen Pneumothorax in der Behandlung der Lungentuberkulose. Zeitschrift für Tuberkulose 1908;12:1.

Stokes W. A treatise on the diagnosis and treatment of diseases of the chest. Dublin: Hodges and Smith, 1837:part I, 531.

Toussaint E. Sur la marche de la tuberculisation pulmonaire: infuence du pneumothorax. University of Paris, thesis No 296, 1880.

Walshe WH. Practical treatise on diseases of the lung. Philadelphia, 1860:250.

Zorini AO. The Carlo Forlanini Institute of INPS. Rome: Carlo Forlanini Institute, 1971. 